\title{
Posterior Pigment Epithelium
}

National Cancer Institute

\section{Source}

National Cancer Institute. Posterior Pigment Epithelium. NCI Thesaurus. Code C33374.

Highly pigmented epithelium covering the posterior surface of the iris. 